\title{
Interlaminar Fracture Toughness of Carbon Fibre/RTM6-2 Composites Toughened with Thermoplastic-coated Fabric Reinforcement
}

DOI:

10.1016/j.compositesb.2017.08.003

\section{Document Version}

Accepted author manuscript

Link to publication record in Manchester Research Explorer

Citation for published version (APA):

Wilkinson, A., Wu, Z., \& Yi, X-S. (2017). Interlaminar Fracture Toughness of Carbon Fibre/RTM6-2 Composites Toughened with Thermoplastic-coated Fabric Reinforcement. Composites. Part B: Engineering, 130, 192-199. https://doi.org/10.1016/j.compositesb.2017.08.003

Published in:

Composites. Part B: Engineering

\section{Citing this paper}

Please note that where the full-text provided on Manchester Research Explorer is the Author Accepted Manuscript or Proof version this may differ from the final Published version. If citing, it is advised that you check and use the publisher's definitive version.

\section{General rights}

Copyright and moral rights for the publications made accessible in the Research Explorer are retained by the authors and/or other copyright owners and it is a condition of accessing publications that users recognise and abide by the legal requirements associated with these rights.

\section{Takedown policy}

If you believe that this document breaches copyright please refer to the University of Manchester's Takedown Procedures [http://man.ac.uk/04Y6Bo] or contact uml.scholarlycommunications@manchester.ac.uk providing relevant details, so we can investigate your claim.

\section{OPEN ACCESS}




\title{
Interlaminar Fracture Toughness of Carbon Fibre/RTM6-2 Composites Toughened with Thermoplastic-coated Fabric Reinforcement
}

\author{
Zijie $\mathrm{Wu}^{\mathrm{a}}, \mathrm{Xiao-Su} \mathrm{Yi}{ }^{\mathrm{b}}$, Arthur Wilkinson $^{\mathrm{a} *}$ \\ ${ }^{\text {a }}$ North West Composites Centre, School of Materials, University of Manchester, Manchester M13 9PL, UK. \\ ${ }^{\mathrm{b}}$ Beijing Institute of Aeronautical Materials, Beijing, China \\ *Corresponding author. Tel.: +44 (0)161 3065691. E-mail: Arthur.Wilkinson@manchester.ac.uk
}

\begin{abstract}
Thermoplastic toughening of epoxy (RTM6-2)/ carbon fibre (CF) laminate composites without modification of the resin is reported, in which a CF fabric coated with 20 weight \% of a poly (aryl ether ketone) (PAEK) was used to toughen composites. Dissolution of the PAEK during resin infusion, with subsequent reaction-induced phase separation and phase inversion during curing, formed PAEK-rich continuous layers with dispersed RTM6-rich particles within the interlaminar regions. These layers provided significant toughening during interlaminar fracture testing, in which the Mode I and Mode II fracture energies for the toughened system increased from $216 \pm 7.2$ to $751 \pm 105$ and $857 \pm 99 \mathrm{Jm}^{-2}$ to $3316 \pm 372 \mathrm{Jm}^{-}$ ${ }^{2}$, respectively. Thus, coating of the $\mathrm{CF}$ fabric with PAEK avoided the significant increases in viscosity observed with resin systems containing dissolved thermoplastics; whilst generating multiphase toughening layers at the $\mathrm{CF}$ fabric - matrix interfaces which provide efficient interlaminar toughening.
\end{abstract}

\section{Key Words}

Polymer-matrix composites (PMCs); Fracture toughness; Interface/interphase.

\section{Introduction}

Advanced carbon fibre $(\mathrm{CF})$ - epoxy resin composites are now used widely by the aerospace industry, due mainly to their outstanding specific mechanical properties [1]. RTM6 is a common commercial aerospace-grade epoxy system, qualified for infusion processing by the European and USA aerospace industry for more than 20 years. Due to the highly crosslinked nature of aerospace-grade epoxy resins, an RTM6 matrix is mechanically strong but also exhibits relatively low fracture resistance [2]. A common approach to increasing the fracture toughness of CF-epoxy composites is to dissolve a thermoplastic toughening modifier in the resin (such as polyether imide [3, 4], polysulfone [5], polyether sulfone [6] polyphenylene ether [7, 8], polyethylene terephthalate [9], polyphenylene oxide [10], or polyhydroxy ether 
bisphenol A (phenoxy) [11] ), which subsequently phase separates during curing to form a toughening dispersed phase [3]. However, the viscosity of an epoxy resin system increases significantly when a high molecular weight thermoplastic toughening component is introduced, causing severe problems in traditional infusion processes such as resin transfer moulding and resin infusion. To address this problem Cytec developed Priform ${ }^{\mathrm{TM}}$, in which the reinforcing fibres were commingled with soluble, thermoplastic fibres that dissolved in the (untoughened) epoxy resin during moulding to form a toughening dispersed phase [12]. Similarly, Wong et al reported a toughening concept based on dissolvable phenoxy fibres, and Zhang et al used phenoxy interleaves to toughen a CF/ RTM6 composite which resulted in a 3.4 fold increase in interlaminar fracture energy [13]. However, these methods were relatively complex and expensive to produce. As an alternative, Yi et al introduced the concept of "ex situ" (ES ${ }^{\mathrm{TM}}$ ) toughening which uses relatively simple web-coating techniques to apply a thermoplastic coating to both sides of a $\mathrm{CF}$ fabric. In this technique, the toughening polymer is concentrated at the matrix-reinforcement interface, giving a high local concentration of thermoplastic to increase the interlaminar toughness of laminate composites produced by dry-fabric processing techniques Preliminary studies have shown the technique to work well with a low viscosity, untoughened epoxy system, bismaleimide and polybenzoxazine resins [14-16]. However, no study has addressed the toughening of highlycrosslinked aerospace-grade epoxy resin systems, such as RTM6, using thermoplastic-coated fabrics. In the present study, uncoated T300 CF and ES-CF fabric/RTM6 composites were manufactured using a novel resin infusion/ hot-press hybrid process, and their mode I and mode II interlaminar fracture behaviour studied.

\section{Experimental}

\subsection{Materials}

The two carbon fibre (CF) fabrics used in this study, one uncoated and the other a coated ES ${ }^{\text {тм }}$ fabric, were supplied by the Beijing Institute of Aeronautical Materials (BIAM). Both were a uniweave unidirectional CF fabric with an areal density of $167 \pm 5 \mathrm{gsm}$; the warp yarn was T300 CF and the weft yarn was polyester fibre spaced at $3 \mathrm{~mm}$. The ES fabric was manufactured by BIAM by coating both sides of the $\mathrm{CF}$ fabric with an amorphous poly(aryletherketone), PAEK, thermoplastic toughening component (Xuzhou Engineering Plastics), the structure of which is shown in Fig.1. The coating level was measured at 20.0 \pm 0.3 wt. $\%$ by applying resin digestion to the ES fabric (following ASTM D3171 procedure B [17]). 


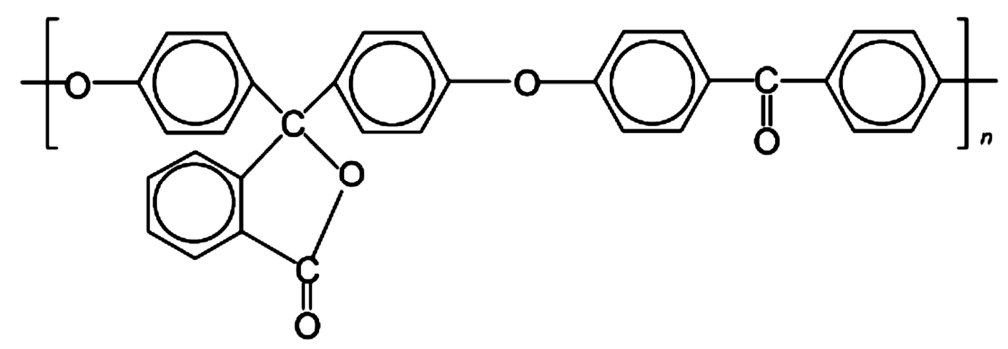

Fig.1. Molecular structure of the PAEK toughening coating. [14, 15]

\subsection{Manufacturing}

\subsubsection{Processing Behaviour of Epoxy Resin Matrix System}

The epoxy resin system used was RTM6-2, purchased from Hexcel. RTM6-2 is a twocomponent system containing the same ingredients as the original single-component RTM6 system. Samples of part A (tetraglycidyl methylene dianiline) and part B (4,4'methylenbis(2-isopropyl-6-methylaniline and 4,4'-methylenbis(2,6-diethylaniline)) of the RTM6-2 system (here now shortened to RTM6) were preheated at $95{ }^{\circ} \mathrm{C}$ until liquid, then mixed at a weight ratio of WA:WB $=100: 68.2$ in a glass bottle within an oil bath set at $80{ }^{\circ} \mathrm{C}$. A Heidolph RZR 2052 overhead stirrer was used to mix the system at $200 \mathrm{rpm}$ for 30 minutes, after which the system was degassed in a vacuum oven at $80^{\circ} \mathrm{C}$ for 1 hour. Samples for DSC measurements were prepared immediately after mixing and the rest of the mixed system was stored in a freezer to be used for rheology measurements and resin infusion. The dynamic mechanical properties of the composites were determined using a Perkin Elmer DMA8000 in dual cantilever bending mode. Rectangular specimens (40 x 10 × $3 \pm 1 \mathrm{~mm})$ were tested at a frequency of $1 \mathrm{~Hz}$ from $30{ }^{\circ} \mathrm{C}$ to $300{ }^{\circ} \mathrm{C}$ at a ramp rate of $5{ }^{\circ} \mathrm{C} \mathrm{min}^{-1}$. The $\mathrm{T}_{\mathrm{g}}$ of the matrix was determined using both the $\tan \delta$ peak temperature for the transition and the onset of the drop in storage modulus $\mathrm{E}^{\prime}$ at the start of the transition (sometimes termed the engineering $\mathrm{T}_{\mathrm{g}}$ ). Isothermal DSC was conducted at five temperatures, 100, 120, 140, 160 and $180{ }^{\circ} \mathrm{C}$ to simulate the thermal history of the rheometry studies. Thus, the degree of cure at any time $\mathrm{t}, \alpha_{\mathrm{t}}$, during an isothermal DSC run can be calculated from the value of reaction enthalpy at time $\mathrm{t}, \Delta \mathrm{H}_{\mathrm{t}}$, using equation 1 .

$$
\alpha_{t}=\Delta H_{t} / \Delta H_{\text {total }}
$$

Oscillatory shear rheological experiments were performed using a Thermo Scientific Haake Modular Advanced Rheometer System (MARS II) fitted with $35 \mathrm{~mm}$ diameter disposable aluminium parallel plates set at a $0.5 \mathrm{~mm}$ gap. Measurements were taken at $2.00 \% \pm 0.25 \%$ 
controlled deformation auto-strain and $1 \mathrm{~Hz}$ frequency. Complex viscosity, $\eta^{*}$, was measured during two types of thermal profiles: 1) Isothermal testing at $100,120,140,160$ and $180{ }^{\circ} \mathrm{C}$ for 300 minutes; 2) following the manufacturer's recommended infusion cycle of $60 \mathrm{~min}$ at $80{ }^{\circ} \mathrm{C}$ and $120 \mathrm{~min}$ at $120^{\circ} \mathrm{C}$ at a ramp rate of $1^{\circ} \mathrm{C}$ per minute.

\subsubsection{Composite Manufacturing}

Resin Infusion (RI) and Hybrid RI-Hot Press Moulding

For RI, the fabrics were cut into $400 \mathrm{~mm} \times 400 \mathrm{~mm}$ plies using a Lectra Vector TechTex FX ply cutter. Firstly, a layer of release agent (700NC, Frekote) was applied to the surface of a flat aluminium tool plate and allowed to dry. The fabric stack was then placed on the tool plate. The set up for RI is shown in Fig. 2, with spiral-split inlet and outlet tubes at two sides, peel ply (a plain woven nylon fabric) on top of the fabric stack and a distribution mesh (used to distribute the resin) placed over the top of the inlet spiral tube and over the peel-ply. Finally, the whole system was sealed with bagging film using tacky tape. For RI; the mixed RTM6 was preheated to $80{ }^{\circ} \mathrm{C}$ in an oven and the mould to $120{ }^{\circ} \mathrm{C}$ on a heated vacuum table (Elkom GmbH Vakutherm Membrane Press), then the resin was infused under vacuum and once the fabric stack was fully saturated both the inlet and outlet tubes were sealed with Hoffman clips. The lay-up was then placed in an oven and cured at $160{ }^{\circ} \mathrm{C}$ for 75 minutes. Demoulding was followed by a free standing post-cure in an oven for 120 minutes at $180{ }^{\circ} \mathrm{C}$ (ramp rate $1{ }^{\circ} \mathrm{C} / \mathrm{min}$ ). However, for composites made using RI the fibre volume fractions $\left(\mathrm{V}_{\mathrm{f}}\right)$ of the ES composites (made using the treated ES fabric) were found to be much lower than the T300 composites (made using the untreated T300 CF fabric), at $32.4 \pm 0.7$ and 52.4 $\pm 0.3 \%$ respectively. This was due to the vacuum-only pressure generated during RI providing insufficient compaction of the coated fabric which resulted in laminates approximately $35 \%$ thicker than those made with uncoated fabric. Reductions in compressibility have been observed previously for fabrics with surface modifications that increase the rigidity of the tows [18]. Consequently a hybrid moulding technique (Fig. 2), combining RI with hot-press moulding in a Dr Collin GmbH P300P/M press, was developed to produce laminates with higher fibre volume fractions. The layup was almost the same as RI except that two metal spacer plates were placed either side of the fabric stack in order to stop the moving platen of the hot press at the target thickness of the specimens (e.g. $4 \mathrm{~mm}$ for Mode I and Mode II tests). The moulding cycle proceeded in the same manner as the standard RI, but once the inlet and outlet were sealed the whole assembly was placed in the hot press (at $160{ }^{\circ} \mathrm{C}$ ) and compacted under 10 bar pressure until the spacer bars were reached 
and then left to cure for 75 minutes. Following demoulding, the laminates underwent the same free standing post-cure $\left(120\right.$ minutes at $\left.180{ }^{\circ} \mathrm{C}\right)$.

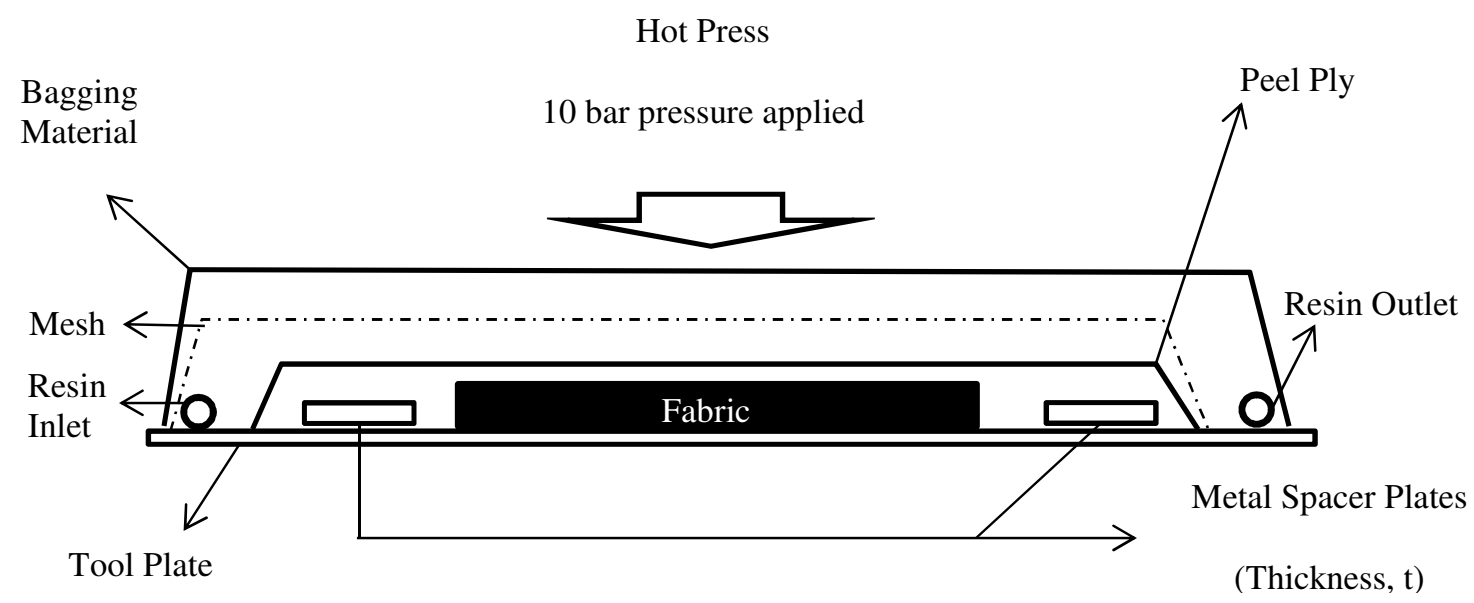

Fig. 2. Schematic of the RI set-up. For the hybrid RI-hot press process the spacer plates are inserted and 10 bar pressure applied in a hot press set at $160{ }^{\circ} \mathrm{C}$.

\subsection{Specimen Preparation and Composite Testing}

Laminate samples for Mode I and Mode II interlaminar fracture tests had 24 layers of fabric all with a ply sequence of $0^{\circ}$ and incorporating mid-plane inserts (Cytec ETFE release film, $13 \mu \mathrm{m}$ thickness) of $70 \mathrm{~mm}$ length (which were later cut to size for the test). Specimens were cut from laminate samples using a Benetec Slida 7000 Manual Sliding Cutter: $40 \mathrm{~mm} \times 10$ $\mathrm{mm}$ for DMTA, $20 \mathrm{~mm} \times 10 \mathrm{~mm}$ for acid digestion and $160 \mathrm{~mm} \times 20 \mathrm{~mm}$ for Mode I and II tests. Each test was conducted on specimens from at least two panel samples. Therefore the \pm standard deviations reported after the mean values in the tables and in the text reflect property variations; both panel-to-panel and specimen-to specimen within the panels.

\subsubsection{Fibre Volume Fraction}

The fibre, matrix and void volume fractions of the composites were determined by removing the epoxy resin matrices by matrix digestion, following ASTM 3171 [17] procedure B which describes digestion using sulphuric acid and hydrogen peroxide.

\subsubsection{Mode-I Interlaminar Fracture Toughness Test- Double Cantilever Beam (DCB)}

Critical strain-energy release rate data in mode-I, $\mathrm{G}_{\mathrm{IC}}$, was determined according to ASTM D5528 [19] in which mode-I crack opening occurs due to a load applied perpendicular to the 
plane of delamination using piano-hinges fitted to the end of a DCB specimen. Specimens (140 mm x $20 \mathrm{~mm}$ ) had their side faces polished, painted white and then marked from the edge of the insert film with vertical lines every $1 \mathrm{~mm}$ up to $50 \mathrm{~mm}$ to facilitate more accurate measurement of crack length by direct visual observation using an image magnifier. Tests were carried out on an Instron 5969 universal testing machine equipped with a $10 \mathrm{kN}$ load cell. $\mathrm{G}_{\mathrm{I}}$ data was calculated by modified beam theory using equation 2 .

$$
G_{I}=\frac{3 P \delta}{2 b(a+I \Delta I)}
$$

Where, $\mathrm{P}$ is the applied load, $\delta$ displacement, $\mathrm{b}$ specimen width, a crack length and $\mathrm{I} \Delta \mathrm{I}$ is calculated using the compliance calibration method as defined in the standard. In accordance with ASTM D5528 [12], three methods were used to determine values of $\mathrm{G}_{\mathrm{IC}}$ at the initiation of delamination; visual observation, onset of non-linearity and 5\% offset/maximum load (giving $\mathrm{G}_{\mathrm{IC}-\mathrm{V} i \mathrm{~s}}, \mathrm{G}_{\mathrm{IC}-\mathrm{NL}}$ and $\mathrm{G}_{\mathrm{IC}-\mathrm{Max}}$, respectively). Following initiation of delamination propagation values, $\mathrm{G}_{\mathrm{IC}-\mathrm{Prop}}$, was determined as a function of crack length a.

\subsubsection{Mode-II Interlaminar Fracture Test; 4-Point Bend End-Notched Flexure (4-ENF)}

The 4-ENF test was used to determine Mode-II strain-energy release rate $\left(\mathrm{G}_{\mathrm{II}}\right)$ data, and the procedure followed those of previous studies. [20-22] The configuration and the dimensions of a 4-ENF specimen are shown in Fig.3. The spans for the loading rollers and the supporting rollers were $60 \mathrm{~mm}$ and $100 \mathrm{~mm}$, respectively, therefore the effective initial delamination length $\left(\mathrm{a}_{0}\right)$ was $30 \mathrm{~mm}$. As with the mode-I specimens, the sides of each specimen were painted white and a scale was marked every $1 \mathrm{~mm}$ for $50 \mathrm{~mm}$.

The 4-ENF tests were performed using an Instron 5969 universal testing machine fitted with a $10 \mathrm{kN}$ load cell. The crosshead displacement speed was $5 \mathrm{~mm} / \mathrm{min}$ for pre-cracking (to extend the starter crack beyond the resin pocket at the end of the insert) [23], $0.5 \mathrm{~mm} / \mathrm{min}$ for the remaining length and $10 \mathrm{~mm} / \mathrm{min}$ for return of the crosshead after the delamination length reached around $40 \mathrm{~mm}$. The $\mathrm{G}_{\mathrm{II}}$ data was calculated using equation 3. Where, $\mathrm{P}$ is load, $\mathrm{b}$ specimen width, a delamination length and $\partial \mathrm{C} / \partial \mathrm{a}$ is the gradient from a compliance curve plotted according to modified beam theory (MBT) [19]. As with the mode-I tests, critical values of $\mathrm{G}_{\text {IIC-Vis }}$, $\mathrm{G}_{\text {IIC-NL }}, \mathrm{G}_{\text {IIC-Max }}$ and $\mathrm{G}_{\text {IIC-Prop }}$ were determined. 


$$
G_{I I}=\frac{P^{2}}{2 b} \frac{\partial C}{\partial a}
$$

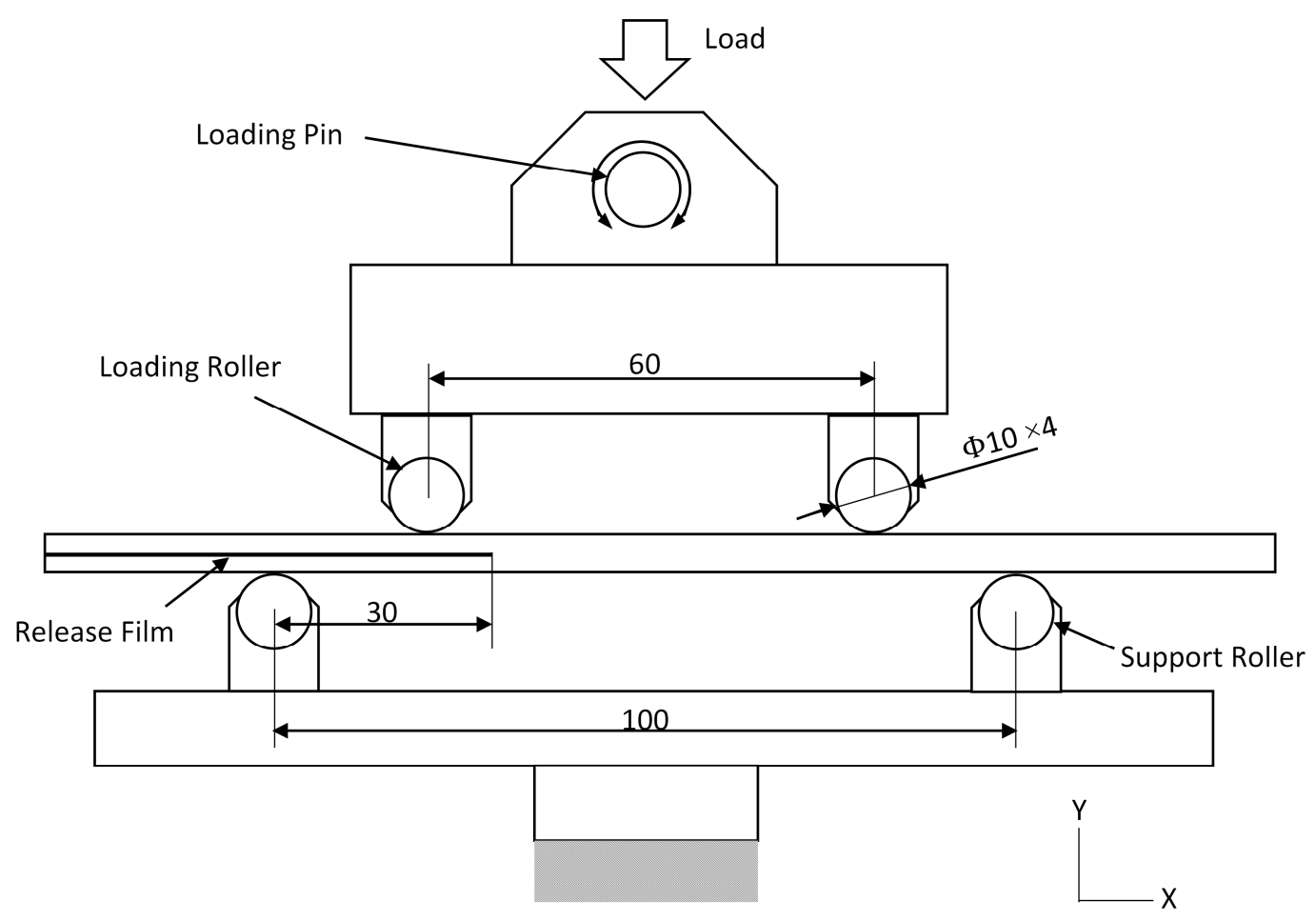

Fig.3. Fixture for 4-ENF mode-II testing; all dimensions in mm.

\subsubsection{Scanning Electron Microscopy (SEM)}

Specimens to be observed using SEM were first washed in an ultrasonic bath then dried for $4 \mathrm{~h}$ at $60{ }^{\circ} \mathrm{C}$ under vacuum. To improve contrast in the multiphase matrix, for selected specimens the PAEK phase was solvent etched with tetrahydrofuran (THF) for 72 hours then washed and dried. Prepared specimens were then fixed to aluminium stubs with conductive carbon paper, coated with a layer (200 $\AA$ ) of AuPd alloy in an Edwards S-150-HB sputter coater and finally their edges were painted with conductive silver paint. Images were taken on a Phillips XL30 FEG SEM at $10 \mathrm{kV}$.

\section{Results and Discussion}

\subsection{Resin Viscosity and Degree of Cure}

The complex viscosity data from isothermal rheometry are shown in Fig. 4. During isothermal runs at 100,120 or $140{ }^{\circ} \mathrm{C}$ the initial viscosities are in the range of $30-60 \mathrm{mPa}$ s. 
After 100 minutes, the viscosities remain in the range of $45-65 \mathrm{mPa} \mathrm{s}$ as the degrees of conversion generated (as measured by isothermal DSC) are low, ranging from $7 \%$ to $18 \%$. This indicates that for resin infusion/injection, the processing (resin flow) time could easily be extended to more than 100 minutes without excessive increases in resin viscosity. Upon increasing the temperature to 160 or $180{ }^{\circ} \mathrm{C}$, the resin viscosity increased rapidly within 20 and 40 minutes, respectively, due to the higher degrees of conversion attained $(30 \%$ and $43 \%$ respectively). Based on these results, the mould temperature for manufacture was chosen to be $120^{\circ} \mathrm{C}$.

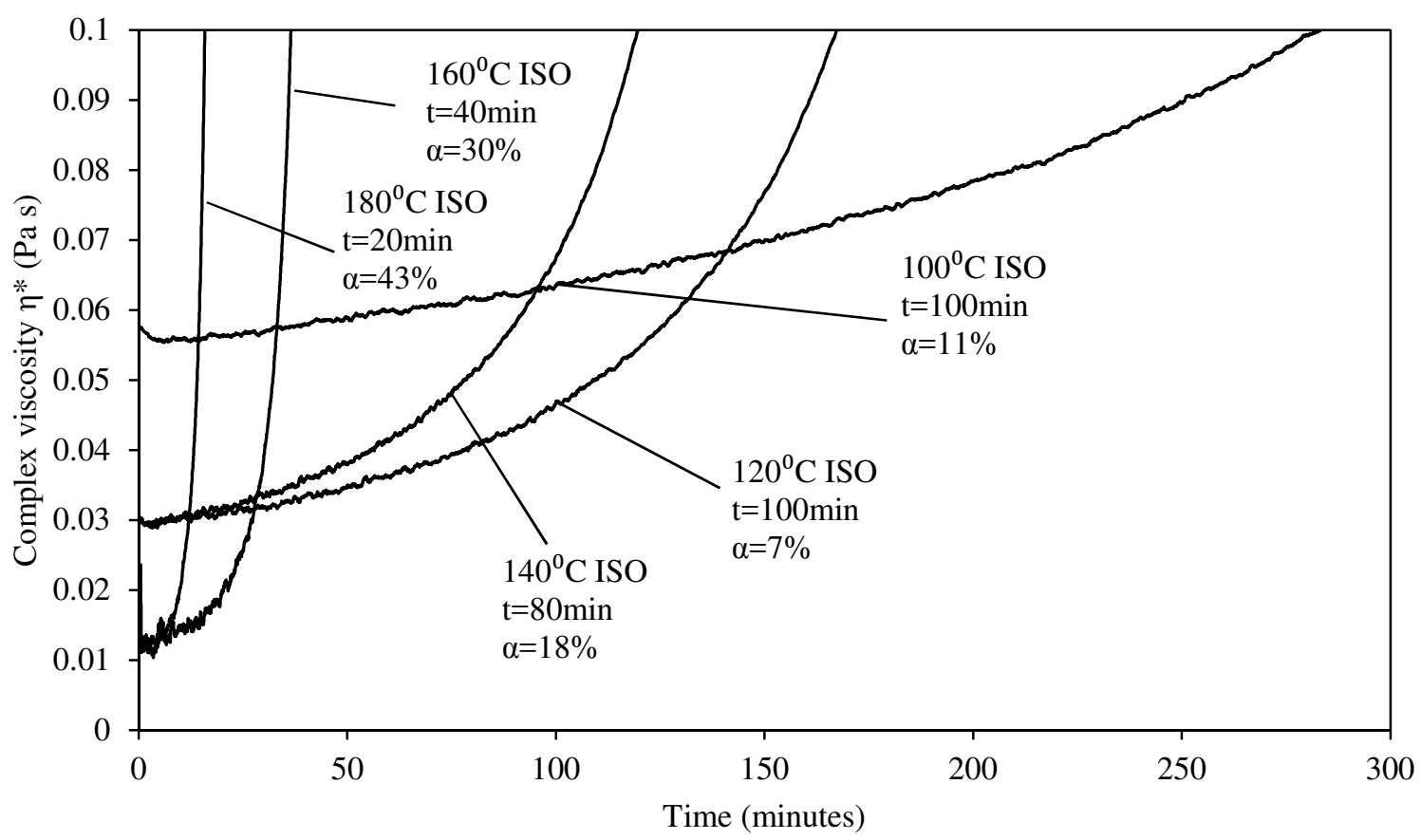

Fig. 4. Experimental isothermal complex shear viscosity $\left(\eta^{*}\right)$ vs. time data and degree of cure ( $\alpha$ data from DSC) for RTM6-2.

The effect on resin viscosity of mixing the A and B components at $80{ }^{\circ} \mathrm{C}$ for 60 minutes, followed by infusion of the resin into a RI lay-up at $120^{\circ} \mathrm{C}$ is shown in the rheometry data in Fig.5, which follows the temperature profile of the standard processing cycle suggested by the RTM6-2 datasheet. Upon heating to $120^{\circ} \mathrm{C}$, the viscosity of the mixed resin drops from 160 to approximately $30 \mathrm{mPa}$ s and rises only slowly to $60 \mathrm{mPa}$ s over a 120 minute period at $120{ }^{\circ} \mathrm{C}$. Thus, the system exhibits good process stability at $120{ }^{\circ} \mathrm{C}$ allowing extended infusion times. 


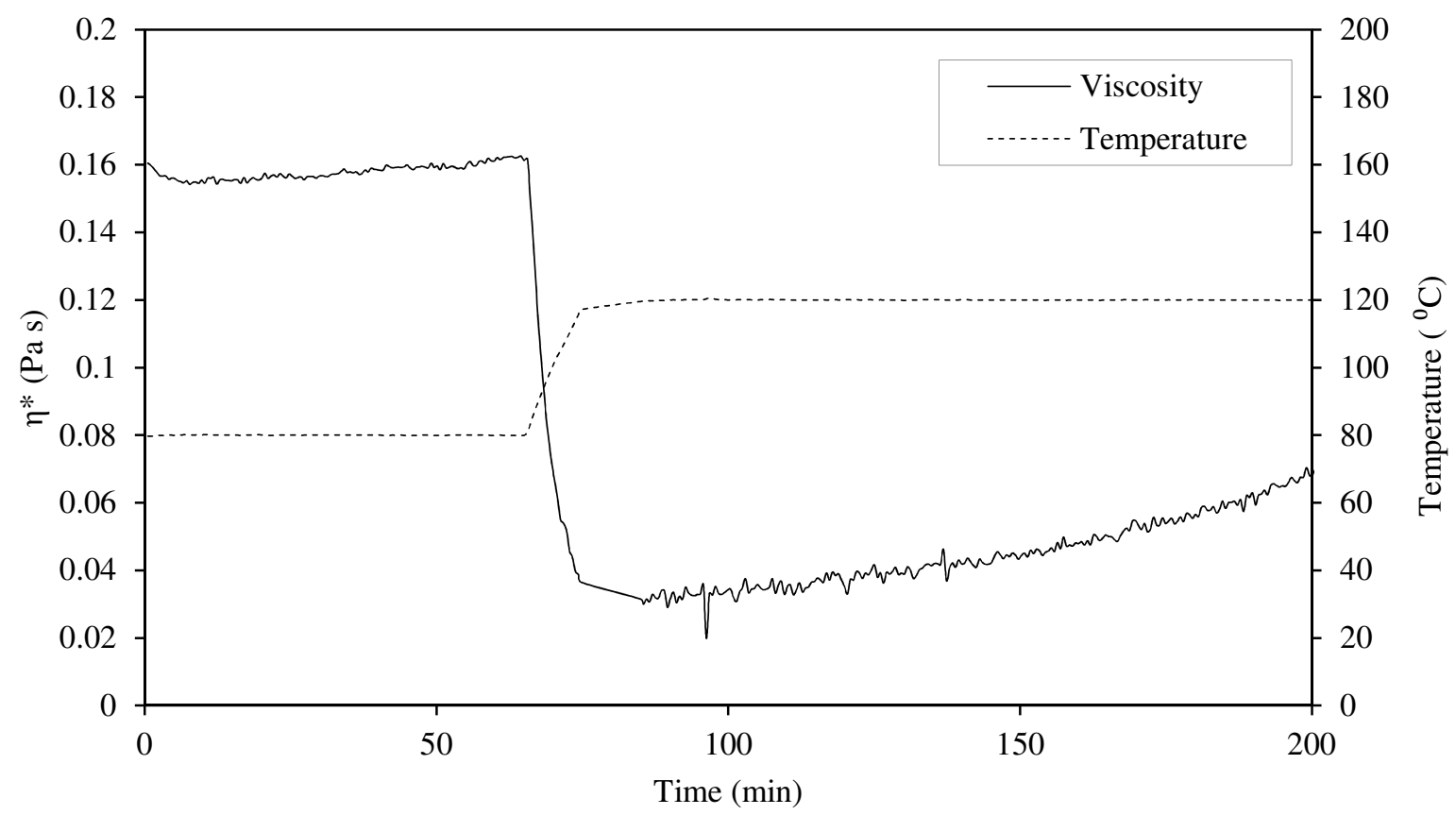

Fig.5. Complex shear viscosity changes versus time for RTM6-2 during a standard resin injection cycle.

Table 1. Typical volume fraction results from matrix digestion of laminates produced using the hybrid RI-hot press (HP) process.

\begin{tabular}{l|lll}
\hline Laminate & $\mathrm{V}_{\mathrm{f}}$ & $\mathrm{V}_{\mathrm{m}}$ & $\mathrm{V}_{\mathrm{v}}$ \\
& $/ \%$ & $/ \%$ & $/ \%$ \\
\hline T300 & $58.7 \pm 0.6$ & $38.9 \pm 1.2$ & $2.4 \pm 0.7$ \\
ES & $56.9 \pm 1.1$ & $39.7 \pm 1.9$ & $3.4 \pm 0.4$ \\
\hline
\end{tabular}

\subsection{Fibre Volume Fractions}

Typical results from resin digestion analysis in Table 1 show both types of laminates produced by the hybrid RI-hot press (HP) process to be now of comparable quality. The HP process generated much higher levels of compaction than RI (due to application of higher pressure), and hence laminates have increased $V_{f}$. 

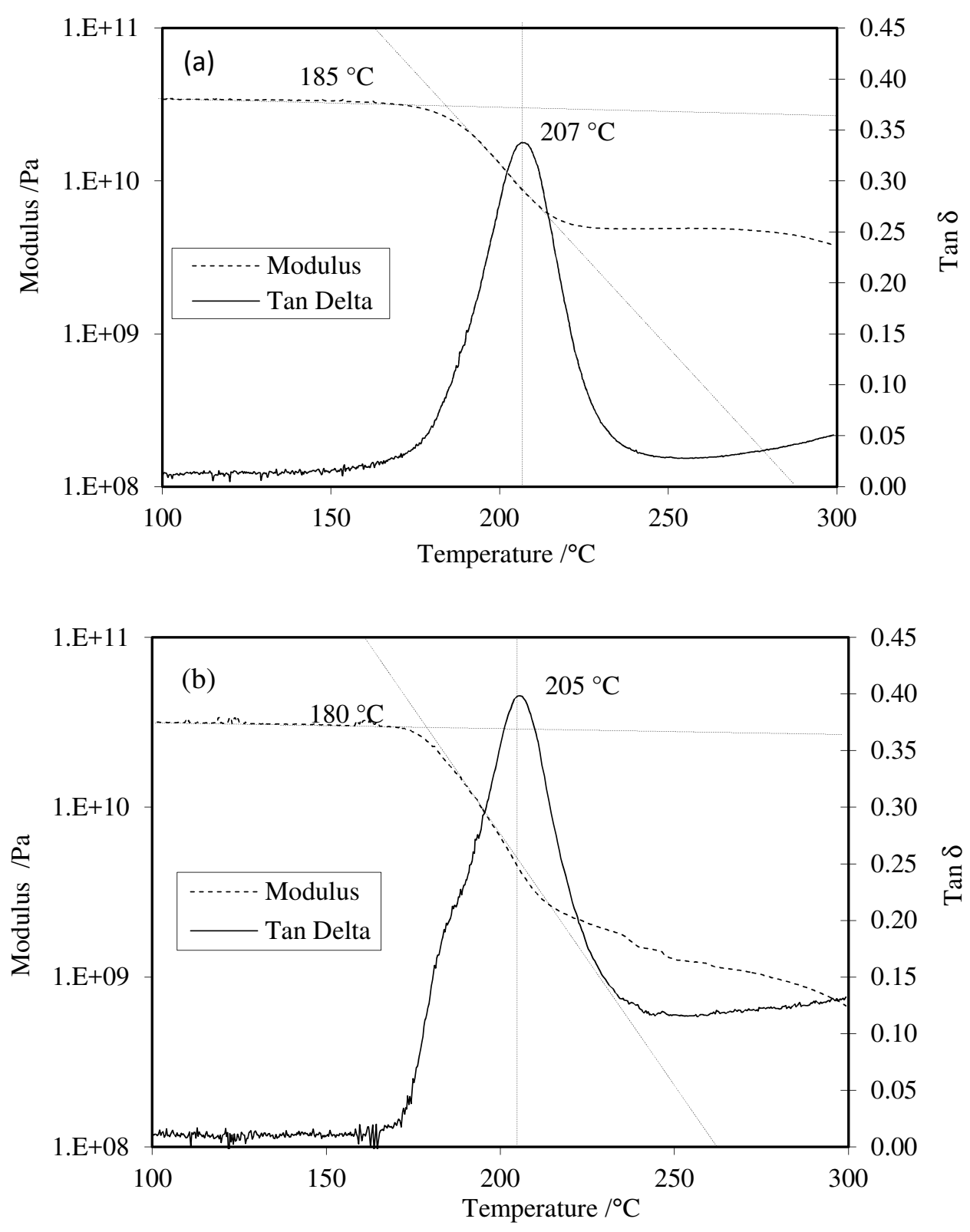

Fig. 6. Typical DMTA storage modulus and damping data for (a) T300 and (b) ES laminates.

\subsection{DMTA}

The DMTA data for the T300 composite are shown in Fig 6a and Table 2 with mean values of $\mathrm{T}_{\mathrm{g}}\left(\tan \delta\right.$ peak) and the engineering $\mathrm{T}_{\mathrm{g}}$ (onset of the drop in storage modulus $\mathrm{E}^{\prime}$ ) of 209 and $186{ }^{\circ} \mathrm{C}$, respectively, and a drop in $\mathrm{E}^{\prime}$ of 1.1 orders of magnitude in the region of the glass transition between 150 and $250{ }^{\circ} \mathrm{C}$. The addition of the PAEK coating, which is reported to have a $\mathrm{T}_{\mathrm{g}}$ of $230{ }^{\circ} \mathrm{C}$ [14], results in significant changes in the tan $\delta$ peak of the ES composite (Fig. 6b); the peak intensity increases to 0.41 (from 0.34 for T300) and the width of the peak at half maximum increases to $29^{\circ} \mathrm{C}$, approximately $60 \%$ wider than the $18{ }^{\circ} \mathrm{C}$ of the T300 composite. In addition, a small shoulder is observed on the tan $\delta$ peak at approximately 180 
${ }^{\circ} \mathrm{C}$ and the ES composite exhibits much higher post- $\mathrm{T}_{\mathrm{g}}$ damping. Thus, the tan $\delta$ data shows that the addition of PAEK to form a multiphase interlaminar region results in a significant degree of interfacial phase mixing in the matrix of the ES composite. However, the $\tan \delta$ peak temperature decreases only slightly (by $3{ }^{\circ} \mathrm{C}$ ) as is often observed for toughening of epoxy resins with a high $T_{g}$ thermoplastic $[24,25]$. Whereas, the increase in post- $T_{g}$ damping increases the drop in $\mathrm{E}^{\prime}$ between 150 and $250{ }^{\circ} \mathrm{C}$ for the $\mathrm{ES}$ composite from 1.1 to 1.35 orders of magnitude.

Table 2. Glass transition temperature $\left(\mathrm{T}_{\mathrm{g}}\right)$ of laminates measured by DMTA.

\begin{tabular}{c|cc}
\hline Sample & Tan $\delta$ Peak $\mathrm{T}_{\mathrm{g}}$ & Drop in $\mathrm{E}^{\prime} \mathrm{T}_{\mathrm{g}}$ \\
& $/{ }^{\circ} \mathrm{C}$ & $/{ }^{\circ} \mathrm{C}$ \\
\hline T300 & $209 \pm 2.3$ & $186 \pm 4.4$ \\
$\mathrm{ES}$ & $206 \pm 0.5$ & $181 \pm 1.4$ \\
\hline
\end{tabular}

\subsection{Interlaminar Fracture Testing}

\subsubsection{Mode I Fracture Energy}

Typical DCB load-displacement curves of T300 and ES specimens are shown in Fig.7. The curves for all these specimens exhibited a linear region at the beginning followed by a downturn in the load. The gradient of the initial linear regions are similar indicating that the addition of PAEK results in relatively little variation in the elastic coefficient of the specimen; this is in agreement with DMTA which measured the log moduli at $30^{\circ} \mathrm{C}$ of specimens from both composites to fall in the range 10.5 \pm 0.2 . Crack initiation was observed to occur at higher displacements and much higher loads for the ES specimens, and for both composites a drop in load was observed as the crack began to propagate, although the load-displacement curve of the ES system is significantly less stable. Thus, the addition of PAEK both delays crack initiation and produces unstable crack propagation through this multiphase matrix, in which the secondary-phase particles can generate one or more of a number of potential additional toughening mechanisms; such as pinning or deflection of the crack, deformation of the secondary-phase particles or microcracking [10]. 


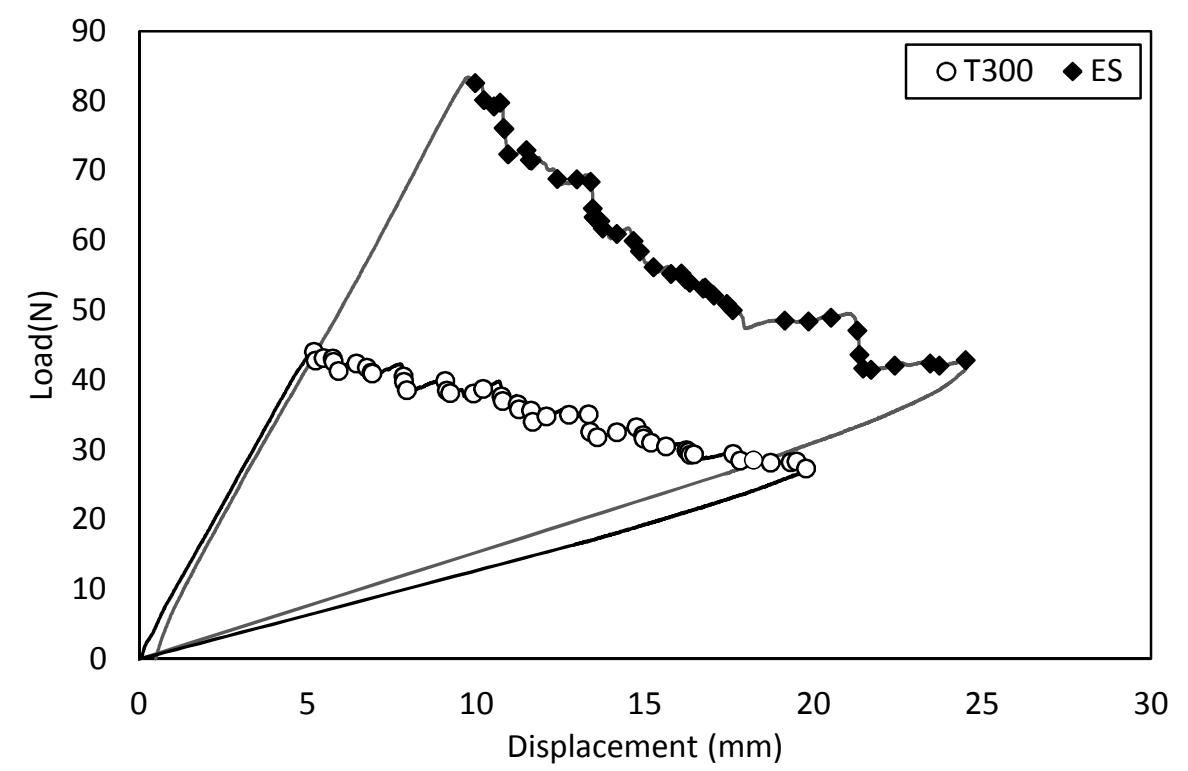

Fig.7. Typical DCB load-displacement curves of T300 and ES composites.

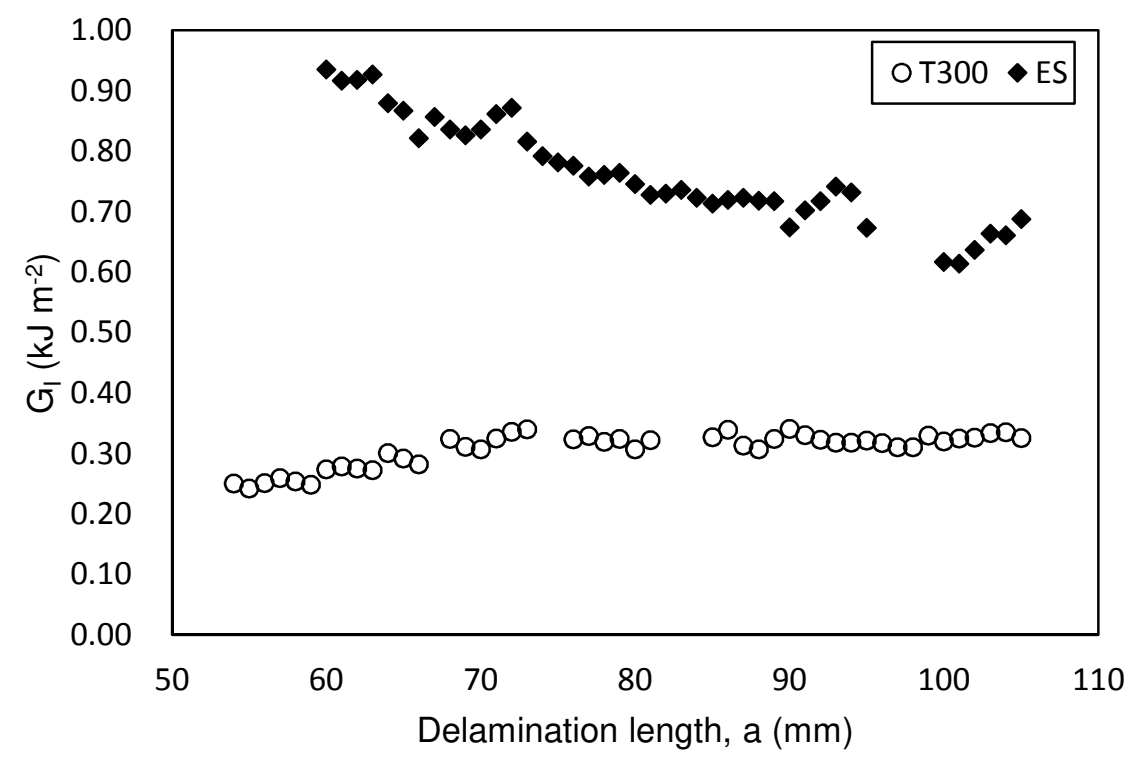

Fig. 8. Typical Mode-I R-curves from T300 and ES DCB tests.

Fig.8 shows typical R-curves of T300 and ES DCB specimens; the average $\mathrm{G}_{\mathrm{I}}$ of the ES specimens for crack propagation is about 3 fold higher than that of the T300. The value of $G_{I}$ for $\mathrm{T} 300$ during crack propagation is relatively stable (mean $\mathrm{G}_{\mathrm{I}}=0.31 \pm 0.07 \mathrm{kJm}^{-2}$ ) compared to the ES (mean $\mathrm{G}_{\mathrm{I}}=0.65 \pm 0.13 \mathrm{kJm}^{-2}$ ) which decreases by up to $25 \%$ with increasing delamination length. Despite this drop, however, the values $\mathrm{G}_{\mathrm{IC}}$ for ES is still much greater. Decreasing R-curve behaviour has been observed previously for thermoplastic-toughened epoxy matrices[26, 27], when the propagating crack deviates from the interlaminar region into either the interfacial or intralaminar regions, paths which provide 
easier crack propagation.

Table 3 and Fig. 8 show that the mean Mode I initiation and propagation $\mathrm{G}_{\mathrm{I}}$ values increased significantly with the use of the PAEK-treated ES fabric, although the standard deviations also increased (to $\pm 13-24 \%$, compared to $\pm 3-9 \%$ ) reflecting the reduction in stability of the crack growth. Thus, the equivalent initiation values show at least a 3 fold increase (factors of $\approx 3.4,3.1$ and 3.5 for 5\%/Max to NL, respectively) and a greater than 2 fold increase (2.1) in the propagation value.

Table 3 - Mean Mode-I fracture energy values.

\begin{tabular}{l|llll}
\hline Sample & $\mathrm{G}_{\mathrm{IC}-\mathrm{Max}}$ & $\mathrm{G}_{\mathrm{IC}-\mathrm{Vis}}$ & $\mathrm{G}_{\mathrm{IC}-\mathrm{NL}}$ & $\mathrm{G}_{\mathrm{IC}}$-prop \\
& $/ \mathrm{Jm}^{-2}$ & $/ \mathrm{Jm}^{-2}$ & $/ \mathrm{Jm}^{-2}$ & $/ \mathrm{Jm}^{-2}$ \\
\hline T300 & $245 \pm 22$ & $240 \pm 19$ & $216 \pm 7.2$ & $313 \pm 29$ \\
ES & $829 \pm 103$ & $730 \pm 178$ & $751 \pm 105$ & $647 \pm 117$ \\
\hline
\end{tabular}
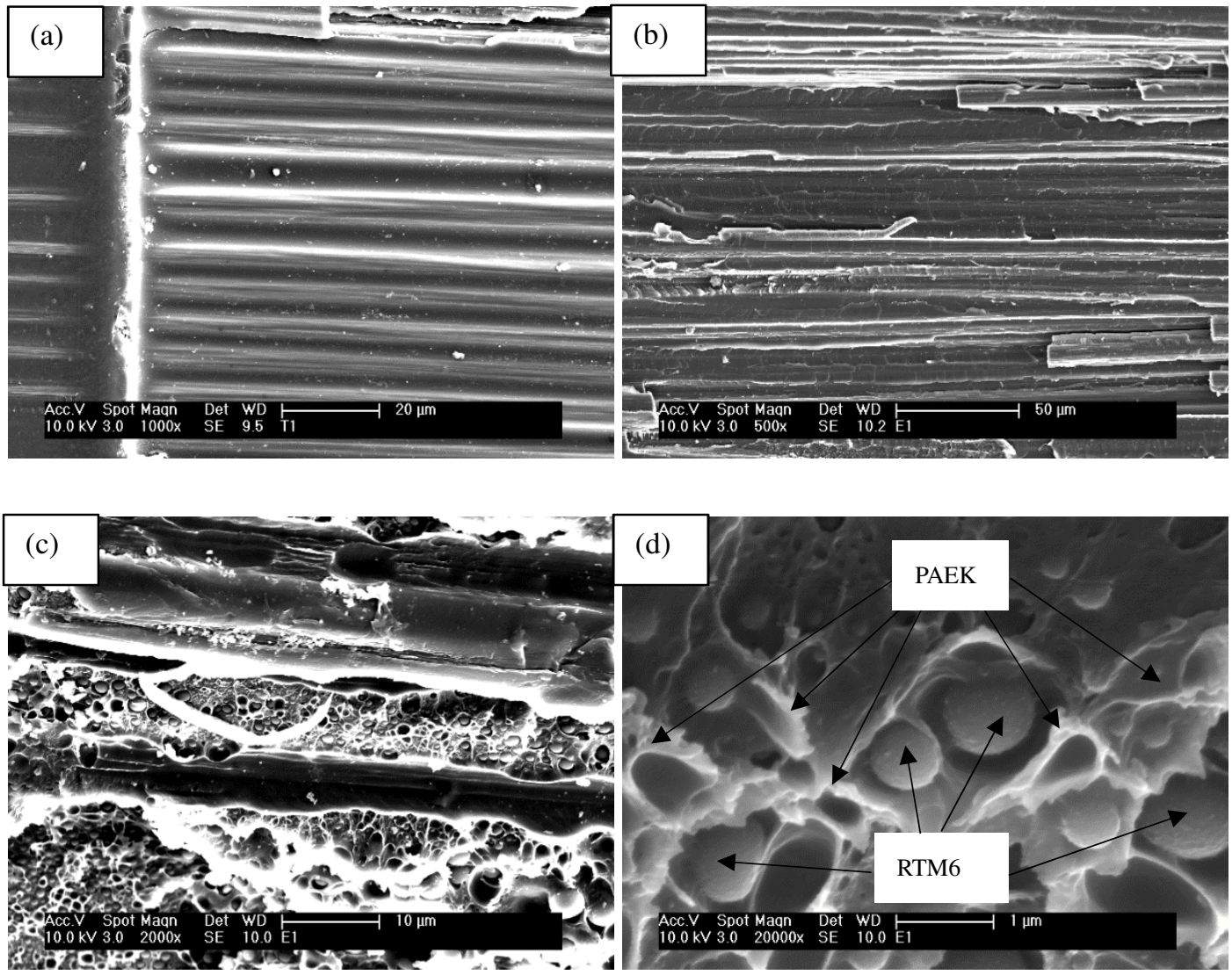

Fig. 9. SEM micrographs of mode I fracture surfaces: (a) onset of T300 x1k, (b) propagation ES x0.5k, (c) THF-etched ES x2k, (d) THF-etched ES x20k 
The SEM image of the fracture surfaces of the T300 composite with a neat RTM6 matrix (Fig. 9 (a)) is typical of a brittle resin-fibre interfacial fracture, in which cracks initiated at the fibre matrix interface then propagated giving rise to river marks and scarps. The fibre-matrix interface also appears to be relatively weak as the fibres showed little sign of matrix adhesion. The fracture surfaces of composites toughened with the PAEK coating were much rougher and Fig.9 (b) from the propagation region of a specimen is indicative of intralaminar fracture. The image in Fig.9 (c) of a THF-etched specimen shows the complex epoxy-PAEK phase structure of the thin interlaminar regions (approximate $100 \mu \mathrm{m}$ ), whereas only singlephase RTM6 material was observed within the intralaminar regions. At a greater magnification, Fig.9 (d) shows a phase inverted particulate structure in the interlaminar region in which RTM6-rich particles are surrounded by a continuous PAEK-rich phase, similar to the morphology reported for a PAEK-toughened BMI by Cheng et al [14]. This morphology forms by reaction-induced phase separation of an initially mixed epoxy-PAEK phase in the interlaminar region followed by phase inversion to form a PAEK-rich continuous phase. The dispersed particles are quite small, with diameters $0.8-1 \mu \mathrm{m}$, and crack propagation has resulted in plastic deformation of these particles into prolate (elliptical) spheroids and in plastic yielding of the continuous PAEK-rich phase. The deformation of RTM6-rich particles and the plastic failure of the PAEK phase results in the significant increase in $\mathrm{G}_{\mathrm{I}}$ values compared to the T300 composite shown in Fig. 8 and Table 4, and results in the crack deviating into the intralaminar region which provides less resistance to propagation, a contributing factor to this deviation being the lack of a toughened multiphase matrix in this region.

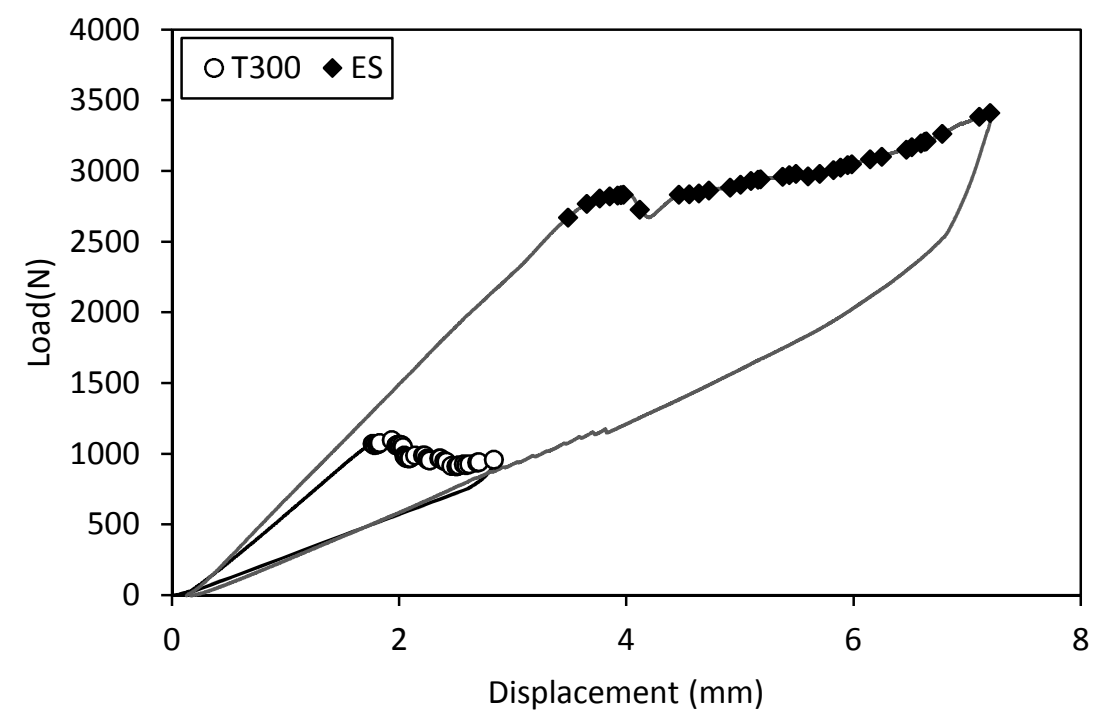

Fig. 10. Typical 4-ENF load-displacement curves of T300 and ES composites. 


\subsubsection{Mode II Fracture Energy}

Typical load-displacement curves of T300 and ES specimens during the 4ENF test are shown in Fig.10. The threshold of the load drop was regarded as crack initiation, with the mean value for the ES composite being approximately 3 fold of that of the T300 and which occurred at a crosshead displacement approximately twice that of the T300, indicating that a Mode II crack propagated much earlier in the latter. In agreement with the Mode-I data (Table 4), the Mode-II data in Table 4 and Fig.11 show very significant increases in all $G_{I I}$ values with the use of the PAEK-coated ES fabric. Thus, the equivalent initiation values show essentially a 4 fold increase (factors of $\approx 4.3,4.2$ and 3.9 fold for Max to NL, respectively) and a greater than 5 fold increase (5.3) in the mean propagation values. In the literature, a study of a similar PAEK-coated (20.2 wt.\%) CF in a BMI matrix [14] reported an increase in $\mathrm{G}_{\text {IIC }}$ of only 1.8 fold. However Ramirez et al [28], reported equivalent 4-5 fold $\mathrm{G}_{\mathrm{IIC}}$ increases for a $\mathrm{CF}$ composite interlaminar-toughened with $40 \mathrm{gsm}$ veils of poly(phenylene sulphide) fibres.

Table 4. Mean Mode-II fracture energy values.

\begin{tabular}{l|llll}
\hline & $\mathrm{G}_{\text {IIC-Max }}$ & $\mathrm{G}_{\text {IIC-Vis }}$ & $\mathrm{G}_{\text {IIC-NL }}$ & $\mathrm{G}_{\text {IIC-prop }}$ \\
& $/ \mathrm{Jm}^{-2}$ & $/ \mathrm{Jm}^{-2}$ & $/ \mathrm{Jm}^{-2}$ & $/ \mathrm{Jm}^{-2}$ \\
\hline T300 & $897 \pm 116$ & $840 \pm 82$ & $857 \pm 99$ & $733 \pm 45$ \\
ES & $3820 \pm 325$ & $3519 \pm 480$ & $3316 \pm 372$ & $3868 \pm 329$ \\
\hline
\end{tabular}

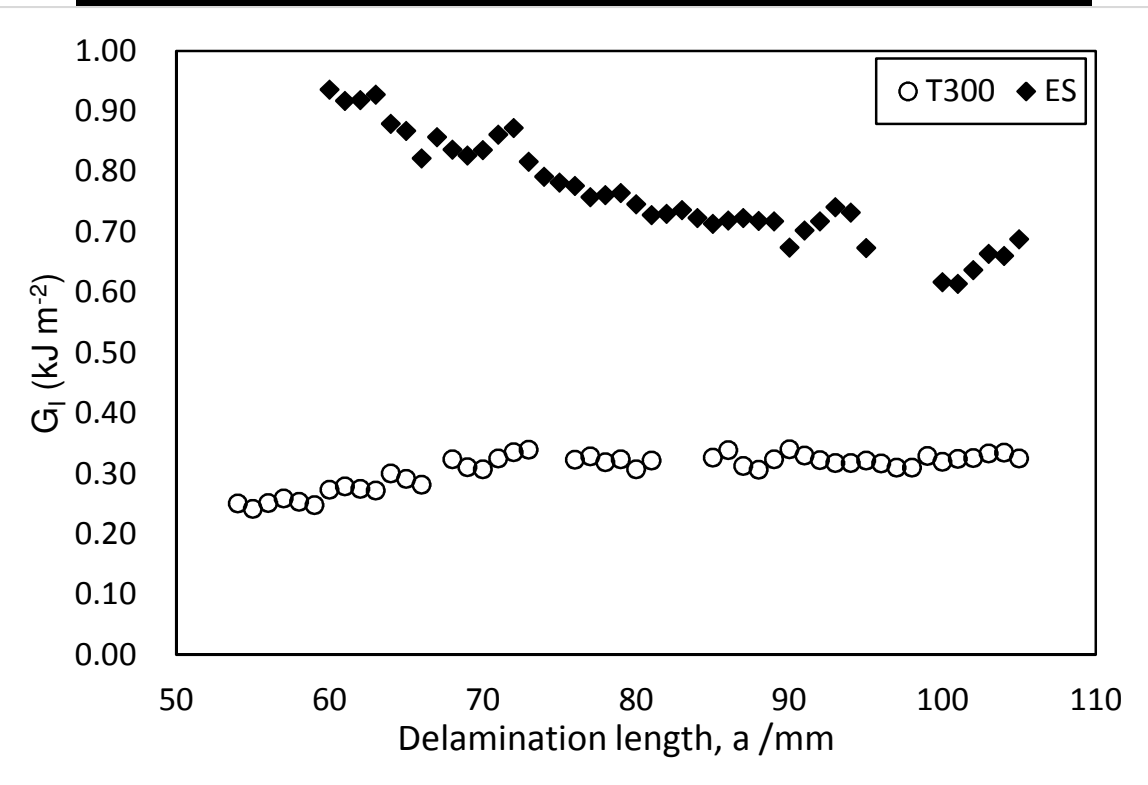

Fig. 11. Typical Mode-II R-curves from T300 and ES 4-ENF tests. 

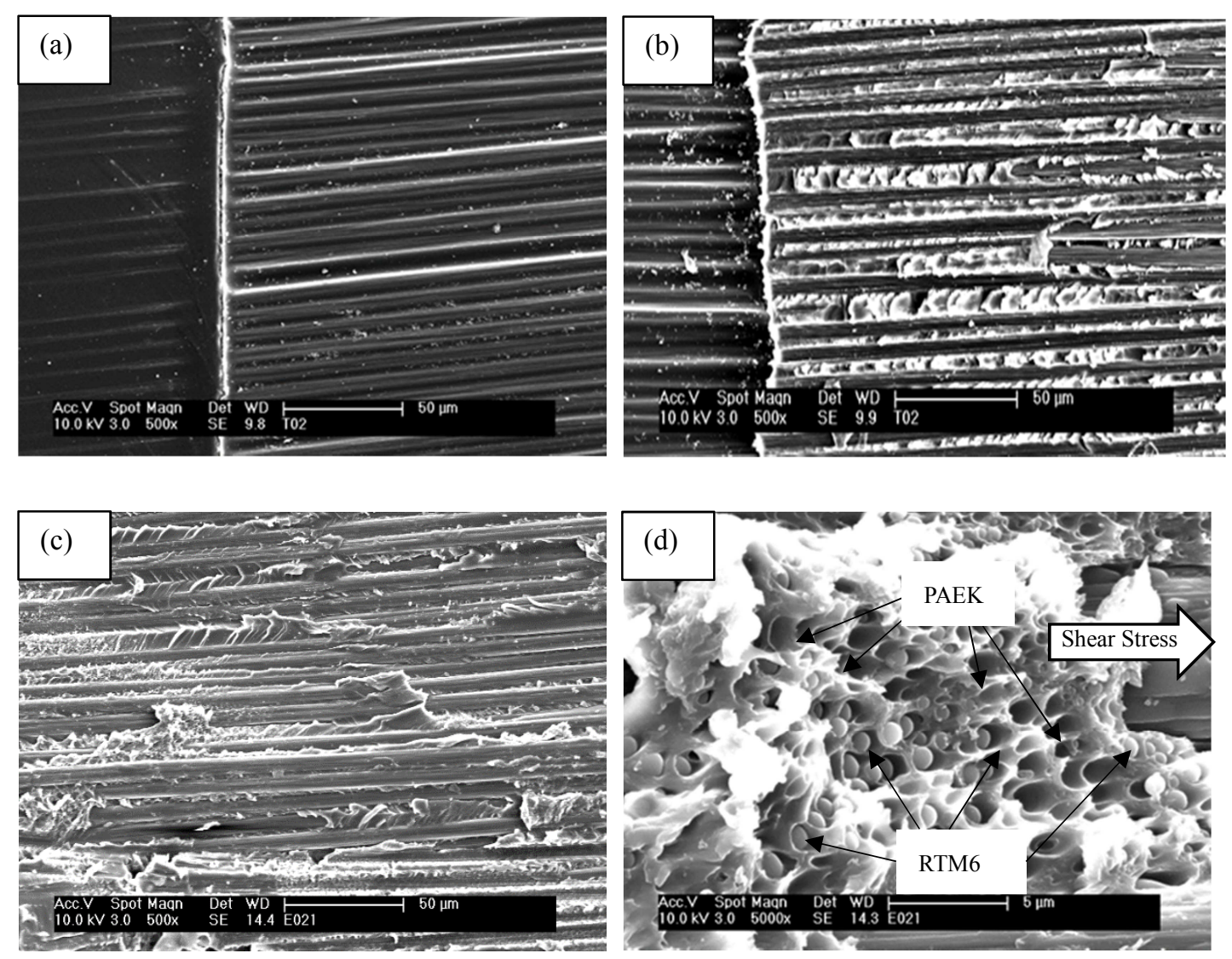

Fig. 12. SEM micrographs of Mode-II fracture surfaces: (a) onset of T300 500×, (b) onset of ES 500×, (c) Propagation ES 500×, (d) THF-etched ES 5000×

Similar to Mode I testing, the T300 specimens in these tests showed much smoother fracture surfaces than the ES specimens. Comparing SEM micrographs of the onset region of both samples (Fig. 12 (a) and (b)) distinct cusps were observed only for the ES specimens; features which also appear in the propagation zone (Fig. 12 (c)). The THF-etched specimen in Fig. 12 (c) shows the phase separation and phase inversion in the multiphase interlaminar region which after Mode II testing shows extensive shear deformation the PAEK-rich continuous phase with little deformation of the RTM6-rich particles.

\section{Conclusions}

The two-component RMT6-2 shows similar rheological behaviour to that reported for RTM6, and the processing temperature was found to be in the range of $100{ }^{\circ} \mathrm{C}$ to $120^{\circ} \mathrm{C}$. The fibre volume fraction of the laminate manufactured by vacuum-only pressure resin infusion was much lower than $55 \%(32.4 \pm 0.7)$, due to reduced compressibility of the coated fabrics, whereas volume fractions of $\geq 55 \%$ were achievable for laminates manufactured by a hybrid 
resin infusion/ hot press process which can apply significant overpressure to the fabric stack. The toughening PAEK coating on the CF resulted in only a small drop in the $\mathrm{T}_{\mathrm{g}}$ of the ES system, down to $206 \pm 2.3^{\circ} \mathrm{C}$ compared to $209 \pm 0.5^{\circ} \mathrm{C}$ for the T300 system. Tough PAEK-rich continuous layers with dispersed RTM6-rich particles of diameter $0.8-1 \mu \mathrm{m}$ formed within the thin interlaminar regions (approximate $100 \mu \mathrm{m}$ ) due to dissolution of the PAEK during the early stages of infusion and curing with subsequent reaction induced phase separation and phase inversion in the later stages of curing. This complex multiphase structure provided significant toughening during interlaminar fracture testing, in which the Mode I fracture energy for the toughened system increased from $216 \pm 7.2 \mathrm{Jm}^{-2}$ to $751 \pm 105 \mathrm{Jm}^{-2}$, a 3-fold increase over the untoughened system. Similarly, the Mode II fracture energy increased from $857 \pm 99 \mathrm{Jm}^{-2}$ to $3316 \pm 372 \mathrm{Jm}^{-2}$, a 4-fold increase. Thus coating of the CF fabric with PAEK toughening agent avoided the significant increases in resin viscosity observed with resin systems containing dissolved thermoplastics, aiding processing, whilst generating multiphase toughening layers at the $\mathrm{CF}$ fabric - matrix interfaces which provide efficient interlaminar toughening of the laminate composites.

\section{Acknowledgements}

Financial support for ZW's PhD study was provided by the Chinese Scholarship Council (CSC) and Beijing Institute for Aeronautical Materials (BIAM, within AVIC).

\section{References}

1. Soutis, C., Carbon fiber reinforced plastics in aircraft construction. Materials Science and Engineering A 2005. 412: p. 171-176.

2. Gerlach, R., et al., Experimental characterisation and constitutive modelling of RTM-6 resin under impact loading. Polymer 2008. 49: p. 2728-2737.

3. Turmel, D.J.-P. and I.K. Partridge, Heterogeneous phase separation around fibres in epoxy/PEI blends and its effect on composite delamination resistance. Composites Science and Technology, 1997. 57(8): p. 1001-1007.

4. Hourston, D.J., J.M. Lane, and H.X. Zhang, Toughening of epoxy resins with thermoplastics: 3. An investigation into the effects of composition on the properties of epoxy resin blends. Polymer International, 1997. 42(4): p. 349-355.

5. Huang, P., et al., Miscibility and mechanical properties of epoxy resin/polysulfone blends. Polymer, 1997. 38(22): p. 5565-5571.

6. Pethrick, R.A., et al., Dielectric, mechanical and structural, and water absorption properties of a thermoplastic-modified epoxy sesin: poly(ether sulfone)-amine cured epoxy resin. Macromolecules, 1996. 29(15): p. 5208-5214.

7. Saalbrink, A., A. Lorteije, and T. Peijs, The influence of processing parameters on interphase morphology in polymer composites based on phase-separating thermoplast/epoxy blends. Composites 
Part A: Applied Science and Manufacturing, 1998. 29(9-10): p. 1243-1250.

8. Venderbosch, R.W., et al., Fibre-reinforced composites with tailored interphases using PPE/epoxy blends as a matrix system. Composites Part A: Applied Science and Manufacturing, 1996. 27(9): p. 895-905.

9. Saalbrink, A., M. Mureau, and T. Peijs, Blends of poly(ethylene terephthalate) and epoxy as matrix material for continuous fibre reinforced composites. Plastics, Rubber and Composites, 2001. 30(5): $\mathrm{p}$. 213-221.

10. Pearson, R.A. and A.F. Yee, Toughening mechanisms in thermoplasticmodified epoxies: 1. modification using poly(phenylene oxide). Polymer, 1993. 34: p. 3658-3670.

11. Wong, D.W.Y., et al., Improved fracture toughness of carbon fibrelepoxy composite laminates using dissolvable thermoplastic fibres. Composites: Part A, 2010. 41: p. 759-767.

12. Hogg, P.J., Toughening of thermosetting composites with thermoplastic fibres. Materials Science and Engineering A, 2005. 412 p. 97-103.

13. Zhang, H., et al., Localized toughening of carbon/epoxy laminates using dissolvable thermoplastic interleaves and electrospun fibres. Composites Part A: Applied Science and Manufacturing, 2015. 79: p. 116-126.

14. Cheng, Q., et al., Ex Situ"concept for toughening the RTMable BMI matrix Composites, Part I: Improving the interlaminar Fracture Toughness. Journal of Applied Polymer Science, 2008. 109: p. 1625-1634.

15. Cheng, Q., et al., Ex-situ concept for toughening the RTMable BMI matrix composites. II. Improving the compression after impact. Journal of Applied Polymer Science, 2008. 108: p. 2211-2217.

16. Jang, J. and H. Yang, Toughness improvement of carbon-fibre/polybenzoxazine composites by rubber modification. Composites Science and Technology, 2000. 60(3): p. 457-463.

17. ASTM, D 3171 Standard test methods for constituent content of composite materials. 2009.

18. Lomov, S.V., et al., Compressibility of carbon woven fabrics with carbon nanotubes/nanofibres grown on the fibres. Composites Science and Technology, 2011. 71(3): p. 315-325.

19. ASTM, D 5528 Standard test method for Mode I interlaminar fracture toughness of unidirectional fiber-reinforced polymer matrix composites. 2007.

20. Cauchi-Savona, Energy absorbing composites for crash energy management, Thesis, in Department of Materials. 2003, Queen Mary, University of London.

21. Schuecker, C. and B.D. Davidson, Evaluation of the accuracy of the four-point bend end-notched flexure test for mode II delamination toughness determination. Composites Science and Technology, 2000. 60: p. 2137-2146.

22. Martin, R.H. and B.D. Davidson, Mode II fracture toughness evaluation using four point bend, end notched flexure test. Plastics, Rubber and Composites, 1999. 28: p. 401-406.

23. Davies, P. and M.L. Benzeggagh, Interlaminar Fracture Studies, in Composite Materials Series: Application of Fracture Mechanics to Composite Materials, R.B. Pipes, Editor. 1989, Elsevier: Amsterdam, Oxford, New York, Tokyo. p. 151.

24. Kim, B.S., T. Chiba, and T. Inoue, Morphology development via reactioninduced phase separation in epoxy/poly(ether sulfone) blends: morphology control using poly(ether sulfone) with functional endgroups. Polymer, 1995. 36(1): p. 43-47.

25. Stein, J. and A.N. Wilkinson, The Influence of PES and Triblock Copolymer on the Processing and Properties of Highly Crosslinked Epoxy Matrices, in ECCM15 - 15th European Conference on 
Composite Materials,. Venice, Italy. p. 24-28

26. Zhang, J. and B.L. Fox, Manufacturing influence on the delamination fracture behavior of the T800H/3900-2 carbon fiber reinforced polymer composites. Materials and Manufacturing Processes, 2007. 22: p. 768-772.

27. Hunt, C., J. Kratz, and I.K. Partridge, Cure path dependency of mode I fracture toughness in thermoplastic particle interleaf toughened prepreg laminates. Composites: Part A, 2016. 87: p. 109114.

28. Ramirez, V.A., P.J. Hogg, and W.W. Sampson, The influence of the nonwoven veil architectures on interlaminar fracture toughness of interleaved composites. Composites Science and Technology, 2015. 110: p. 103-110. 